\title{
Study on Bacterial Flora of Burn Wound Infection: A Need for Microbiological Surveillance in Burn Units
}

\author{
T. Sabetha ${ }^{1}$, A.V.M. Balaji ${ }^{2}$, J. Nithyalakshmi ${ }^{3}$, K. Mohanakrishnan ${ }^{3}$ and G. Sumathi $^{3}$ \\ ${ }^{1}$ Institute of Venerology, Madras Medical College, Chennai, India \\ ${ }^{2}$ Stanley Medical College, Chennai, India \\ ${ }^{3}$ Sri Muthukumaran Medical College and Research Institute, Mangadu, India
}

*Corresponding author:

\begin{tabular}{|c|c|}
\hline & A B S T R A $\mathbf{C}$ \\
\hline & \multirow{8}{*}{$\begin{array}{l}75 \% \text { of the mortality associated with burn injuries is related to infection The aim of the } \\
\text { present study was to identify the bacterial profile of burn wound infection (BWI) in our } \\
\text { setting and determine their susceptibility pattern to commonly used antibiotics. This } \\
\text { prospective study was conducted over a period of one year in a teaching tertiary care } \\
\text { hospital, Chennai. A total of } 100 \text { patients with burns of total body surface area (TBSA) of } \\
20 \% \text { to } 40 \% \text { were included. Three wound swabs on } 1^{\text {st }}, 4^{\text {th }} \text { and } 7^{\text {th }} \text { day were collected } \\
\text { aseptically and processed. Among the } 274 \text { samples collected, } 191 \text { swabs revealed } \\
\text { growth while } 83 \text { showed no growth. Overall isolation rate was found to be } \\
69.7 \% \text { and was predominantly monomicrobial with Gram positive cocci in early swabs. } \\
\text { Subsequent swabs showed } 100 \% \text { colonization with a shift to polymicrobial infection with } \\
\text { predominant isolation of Gram negative bacilli. The most common isolate was } \\
\text { Pseudomonas aeruginosa ( } 35.84 \% \text { ), followed by Klebsiella pneumoniae (27.30\%) } \\
\text { Acinetobacter spp. (20.13\%), Staphylococcus aureus }(8.87 \%) \text {, Escherichia coli }(2.38 \%) \text {. } \\
\text { Gram negative bacteria were found to be highly susceptible to Imipenem and Piperacillin } \\
\text { /Tazobactum. Staphylococcus aureus was } 100 \% \text { sensitive to Linezolid. Knowledge about } \\
\text { specific pattern of burn wound infection and their resistant profile not only enable us to } \\
\text { plan empirical antibiotics to prevent imminent septic episodes but also reduce infection } \\
\text { related mortality in burns patients. }\end{array}$} \\
\hline Keywords & \\
\hline $\begin{array}{l}\text { Bacterial Flora, } \\
\text { Burn Wound } \\
\text { Infection }\end{array}$ & \\
\hline & \\
\hline & \\
\hline Article Info & \\
\hline $\begin{array}{l}\text { Accepted: } \\
04 \text { April } 2017 \\
\text { Available Online: } \\
10 \text { May } 2017\end{array}$ & \\
\hline & \\
\hline
\end{tabular}

\section{Introduction}

Patients with burn injuries are highly susceptible for infection as a result of disruption of the normal skin barrier and accompanying depression of immune response. The burn surface contains a large amount of necrotic tissue and the protein rich wound exudates provides a rich growth medium. So, following the initial period of shock, infection is the major complication and about $75 \%$ of the mortality associated with burn injuries is related to infection. The organisms are mainly derived from the patient's gastro intestinal and upper respiratory tracts as well as from the hospital environment (Al-Aali et al., 2016).

Infection, the risk of which is proportional to the extent of injury, continues to be the predominant determinant of outcome in thermally injured patients. Most of the 
infections are thought to be of nosocomial origin wherein hand and clothing of attending staff has been implicated in many cases. The control of invasive burn wound infection through the use of effective topical chemotherapy, prompt surgical excision, and timely closure of the burn wound has resulted in unsurpassed survival rates. Even so, these measures can cause emergence of antibiotics resistant isolates and treatment failures (Saaiq et al., 2015).

Several studies about the microbial flora have revealed that immediately following burn injury it is predominantly Grampositive organisms, within a week it is replaced by Gram-negative organisms. The distribution of infective agents varies with time and is unique to different hospitals (Mundhada et al., 2015).

The analysis of the isolates and their sensitivity patterns helps us to track the emerging trends to formulate an institutional drug policy for the patients admitted in Burn Unit. Rational antibiotic therapy according to the prevalent strains of organisms should help in reducing the mortality and morbidity associated with burns (Shahzad et al., 2012).

In view of the above literature, this study aims to identify the bacterial profile of burn wound infection (BWI) in our setting and determine their susceptibility pattern to commonly used antibiotics.

\section{Materials and Methods}

This prospective study was conducted over a period of one year in a teaching tertiary care hospital, Chennai. A total of 100 patients with burns of total body surface area (TBSA) of $20 \%$ to $40 \%$ (according to rule of nine) were included. Specimens were three wound swabs collected aseptically from burn area after thorough cleaning with sterile saline. First swab was collected immediately after admission before start of antibiotics on Day 1' and thereafter on Day 4 and Day 10.

\section{Sample processing}

Samples were processed as per standard microbiological procedure. The specimens were subjected to direct gram staining and culture. Identification of aerobic bacteria and its antimicrobial susceptibility pattern was detected as per standard CLSI guidelines.

Antibiotic susceptibility was done by Kirby Bauer disk diffusion method. Among gram negative bacteria, Enterobacteriaceae were tested against Ampicillin $10 \mu \mathrm{g}$, Amikacin 30 $\mu \mathrm{g}$, Tetracycline $30 \mu \mathrm{g}$, Levofloxacin $5 \mu \mathrm{g}$, Cefotaxime $30 \mu \mathrm{g}$, Ceftazidime $30 \mu \mathrm{g}$, Ciprofloxacin $5 \mu \mathrm{g}$ Imipenem $10 \mu \mathrm{g}$, and Piperacillin-Tazobactum 100/10 $\mu \mathrm{g}$. For Pseudomonas species and Acinetobacter species, antibiotic discs like PiperacillinTazobactum 100/10 $\mu \mathrm{g}$, Cefepime $30 \mu \mathrm{g}$, Ceftazidime $30 \mu \mathrm{g}$, Imipenem $10 \mu \mathrm{g}$, Gentamicin $10 \mu \mathrm{g}$, Amikacin $30 \mu \mathrm{g}$ and Ciprofloxacin $5 \mu \mathrm{g}$ were used. For Staphylococcus spp.. Cefoxitin $30 \mu \mathrm{g}$, Erythromycin $15 \mu \mathrm{g}$, Gentamicin $10 \mu \mathrm{g}$, Amikacin $30 \mu \mathrm{g}$,Levofloxacin $5 \mu \mathrm{g}$, Clindamycin $2 \mu \mathrm{g}$, Linezolid $30 \mu \mathrm{g}$, Teicoplanin $30 \mu \mathrm{g}$ were used.

For Enterobacteriaceae - Isolates were considered a potential ESBL producer if the zone of inhibition for ceftazidime was observed to be $<22 \mathrm{~mm}$.Potential ESBL producer was then subjected for ESBL Phenotypic confirmatory test -Disc Diffusion method as recommended by CLSI guidelines for antimicrobial disc susceptibility tests (NCCLS, 2003b).

\section{Phenotypic confirmatory disc diffusion test (PCDDT) for ESBL}

A Mueller Hinton agar plate was taken and a lawn culture of potential ESBL producing 
isolate was made. Then ceftazidime $(30 \mu \mathrm{g})$ disc alone and with clavulanic acid $(10 \mu \mathrm{g})$ were placed at an appropriate distance from each other on the plate and incubated aerobically at $37^{\circ} \mathrm{C}$ overnight. $\mathrm{A} \geq 5 \mathrm{~mm}$ increase in zone diameter for antimicrobial Ceftazidime tested in combination with clavulanic acid in comparison to the zone diameter when tested alone confirmed the organisms to be an ESBL producer by PCDDT.

\section{Detection of MRSA}

Methicillin resistant Staphylococcus aureus (MRSA) detection was done using cefoxitin $30 \mu \mathrm{g}$. Those isolates showed zone of inhibition $<21 \mathrm{~mm}$ considered as MRSA.

\section{Results and Discussion}

A total of 100 patients (44 were males and 56 were females) with $20 \%$ to $40 \%$ burns were included in this study. Majority of the subjects included in our study had sustained second degree burns (52\%) followed by first degree (34\%).(Fig 1)

A total of 274 wound swabs were collected from 100 patients. The reason for less number of samples collected on day 4 and day 10 were due to the fact that patients were either discharged or expired. 191 swabs revealed growth while 83 showed no growth. Isolation rate was found to be $69.7 \%$.(Fig 2)

On admission Monomicrobial infection was common and polymicrobial type of infection was less and it was more with the patients who stayed in the hospital for more than 2 days (Table 1).

The initial swabs were predominantly monomicrobial with gram positive isolates and which is replaced by gram negative isolates in the later swabs, which were also polymicrobial. (Table2). Overall, total number of bacterial isolates obtained was 293.Among them, the most common isolate was Pseudomonas aeruginosa 105 (35.84\%), followed by Klebsiella pneumoniae 80 (27.30\%) Acinetobacter spp. 61(20.13\%), Staphylococcus aureus 22(8.87\%), Escherichia coli 7(2.38\%).

To ensure early and appropriate therapy in burn patients, a frequent evaluation of the wound is necessary. Therefore, a continuous surveillance of microorganisms and a regular update of their antibiotic resistance pattern is essential to maintain good infection control program in the burn unit, thus improving the overall infection-related morbidity and mortality.

In this study the pattern of burn wound microbial colonization was evaluated. The time related changes in the predominant flora was also evaluated throughout the patients hospital stay.

Our study revealed slight female preponderance (56\%) compared to male. This result was in agreement with the finding reported by Mundhada et al., (2015), who observed $54 \%$ in male and $46 \%$ in female. Also, Rajput et al., (1998) found that burn infection in females was $(60 \%)$ while burn infection in males was (40\%). In contrast, DeMacedo and Santos et al., (2005) found that BWI in males $59.1 \%$ was more than females $40.9 \%$. In our country this is likely due to occupational hazards of women working in the kitchen as the kitchen is the most common place prone to burn accidents. In this study, mortality rate was low (8\%) against $19.6 \%$ by Lari et al., (2000). This low rate might be due the fact that we are dealing with patients having TBSA of burn between $20 \%$ and $40 \%$. Majority of the subjects included in our study had sustained second degree burns (52\%) followed by first degree (34\%) (Fig. 1) This was similar to the results 
reported by Al- Akayleh et al., (1999) who showed highest distribution of burn wound infection in burn patients who had sustained second-degree burn (53.9\%).

Isolation rate was found to be $69.7 \%$ (Fig 2) which is comparable to the isolation rate observed by Srinivasan et al., (2009) (86.3\%) and Modi et al., (2013) (85.07). Irrespective of duration of stay, monomicrobial pattern of growth was found to be common than polymicrobial which was in agreement with other studies by Mundhada et al., (2015)and Shahzad et al., (2012)(Table 1)

In a recent study on time-related changes in aerobic bacterial pattern of burn wound infection by Saha et al., (2011), it was found that in burn wounds initially it was gram positive organisms which are gradually superceded by gram negative opportunists that have greater propensity to invade.

Table.1 Type of Growth on wound swab

\begin{tabular}{|l|c|c|c|c|c|c|}
\hline & Day 1 & \% & Day 4 & \% & Day10 & \% \\
\hline Monomicrobial & 30 & $81.08 \%$ & 42 & $55.26 \%$ & 42 & $53.84 \%$ \\
\hline Polymicrobial & 7 & $18.91 \%$ & 34 & $44.73 \%$ & 36 & $46.15 \%$ \\
\hline
\end{tabular}

Table.2 Time related changes in bacterial profile of organisms Isolated

\begin{tabular}{|c|c|c|c|}
\hline Organisms Isolated & Day 1 & Day 4 & Day 10 \\
\hline Monomicrobial & 30 & 42 & 42 \\
\hline Pseudomonas aeruginosa & 7 & 20 & 26 \\
\hline Klebsiellaspp & 4 & 13 & 11 \\
\hline Acinetobacter spp & 2 & 1 & 3 \\
\hline Escherichia coli & -- & 4 & -- \\
\hline CONS & 12 & --- & --- \\
\hline Staphylococcus aureus & 5 & 4 & 2 \\
\hline Polymicrobial & 7 & 34 & 36 \\
\hline Pseudomonas + Acinetobacter & --- & 6 & 8 \\
\hline Pseudomonas + Escherichia coli & --- & 3 & --- \\
\hline Acinetobacter + Klebsiella & --- & 11 & 10 \\
\hline Klebsiella+ CONS & 4 & --- & ---- \\
\hline Pseudomonas + Klebsiella & & 2 & 6 \\
\hline Pseudomonas + CONS & 2 & --- & --- \\
\hline Pseudomonas + Acinetobacter + Klebsiella & $\begin{array}{ll}---- \\
\end{array}$ & 6 & 8 \\
\hline Pseudomonas + Acinetobacter $+\mathrm{S}$. aureus & ---- & 2 & 4 \\
\hline Pseudomonas + S. aureus + Klebsiella & 1 & 4 & $\begin{array}{c}---- \\
-1\end{array}$ \\
\hline
\end{tabular}


Table.3 Resistant Profile of the Organisms

\begin{tabular}{|l|l|l|l|l|}
\hline Organisms & Total No & Resistance type & Positive & Percentage \\
\hline Klebsiella Species & 80 & ESBL & 36 & 45 \\
\hline Escherichia coli & 7 & ESBL & 4 & 57 \\
\hline Staphylococcus aureus & 22 & MRSA & 8 & 36.36 \\
\hline CoNS & 18 & $\begin{array}{l}\text { Methicillin } \\
\text { resistant }\end{array}$ & 5 & 27.77 \\
\hline
\end{tabular}

Fig.1

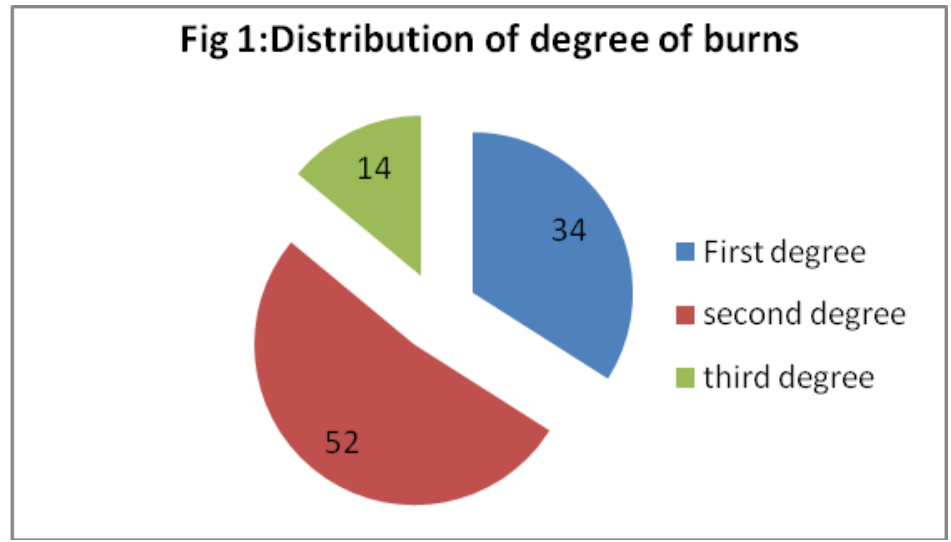

Fig.2

Fig 2:Distribution of bacterial isolates with respect to duration of hospital stay

\begin{tabular}{|c|c|c|c|}
\hline \multicolumn{4}{|l|}{120} \\
\hline \multicolumn{4}{|l|}{100} \\
\hline \multicolumn{4}{|l|}{80} \\
\hline 60 & & & \\
\hline 40 & & & \\
\hline 20 & & & \\
\hline 0 & Day 1 & Day 4 & Day 10 \\
\hline No. of samples & 100 & 94 & 80 \\
\hline Growth positive & 37 & 76 & 78 \\
\hline
\end{tabular}


Fig.3

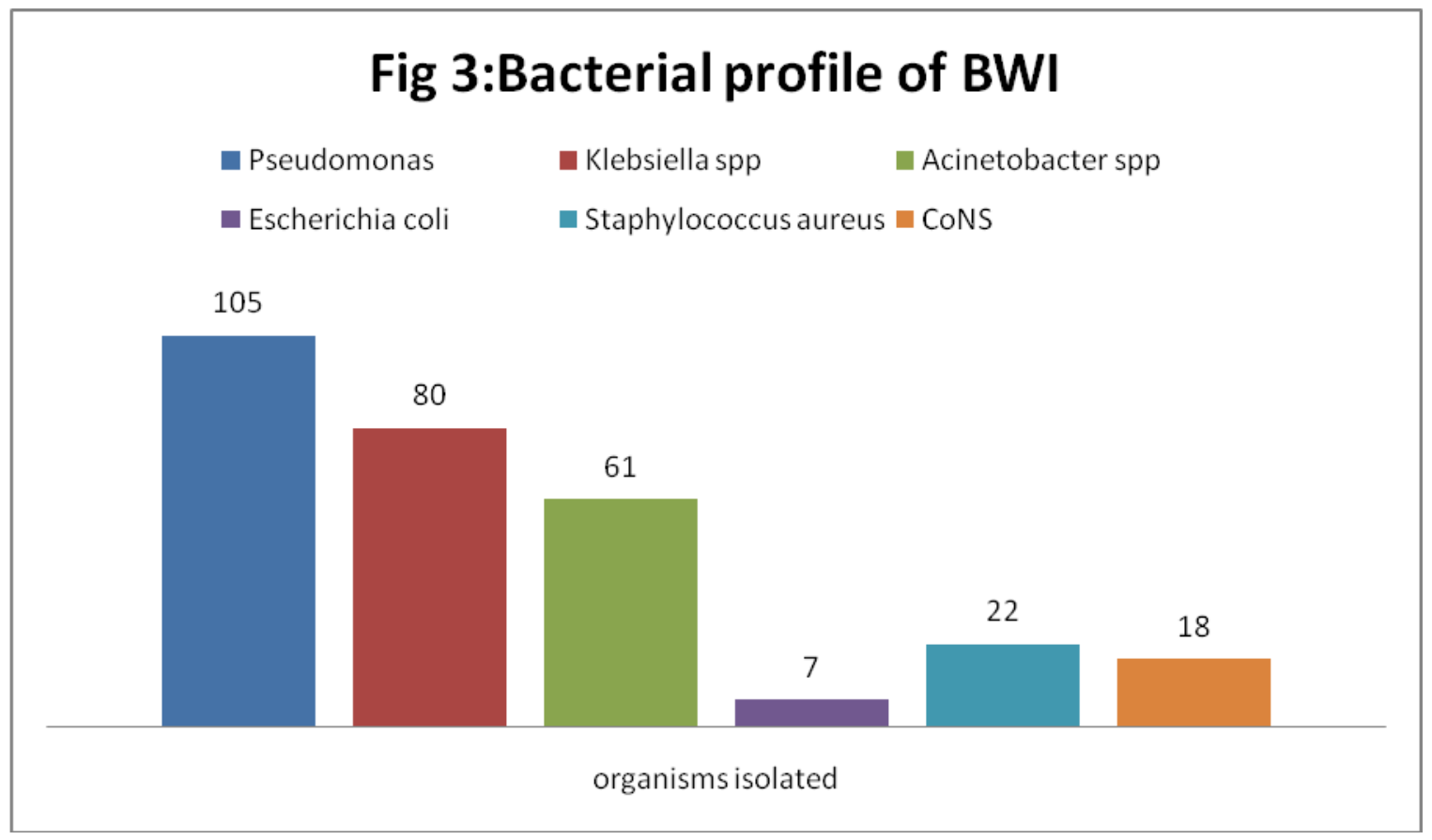

Fig.4 Antibiotic Sensitivity Pattern of Gram Negative Bacilli

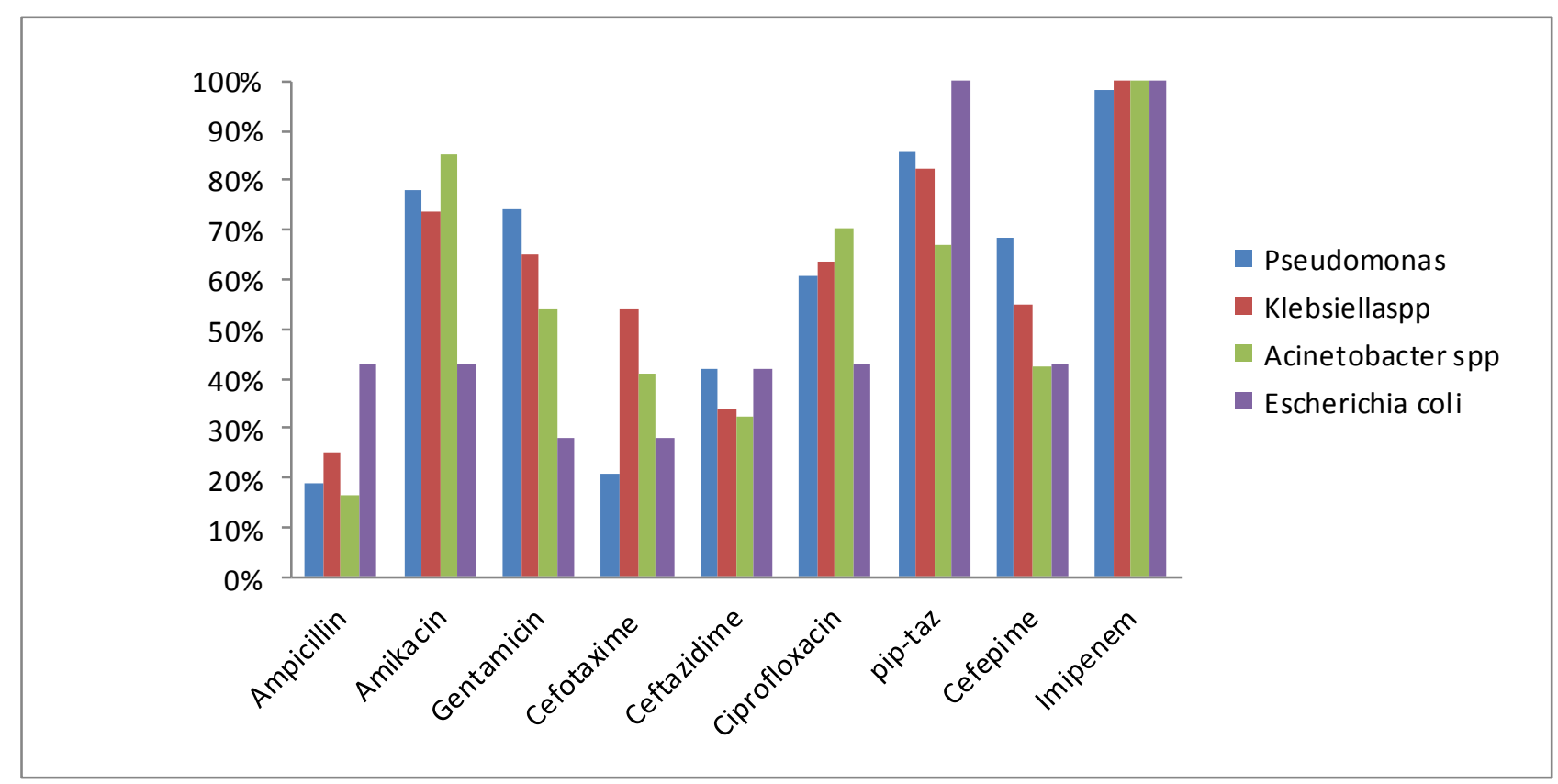


Fig.5 Antibiotic Sensitivity Pattern of Gram Positive Cocci

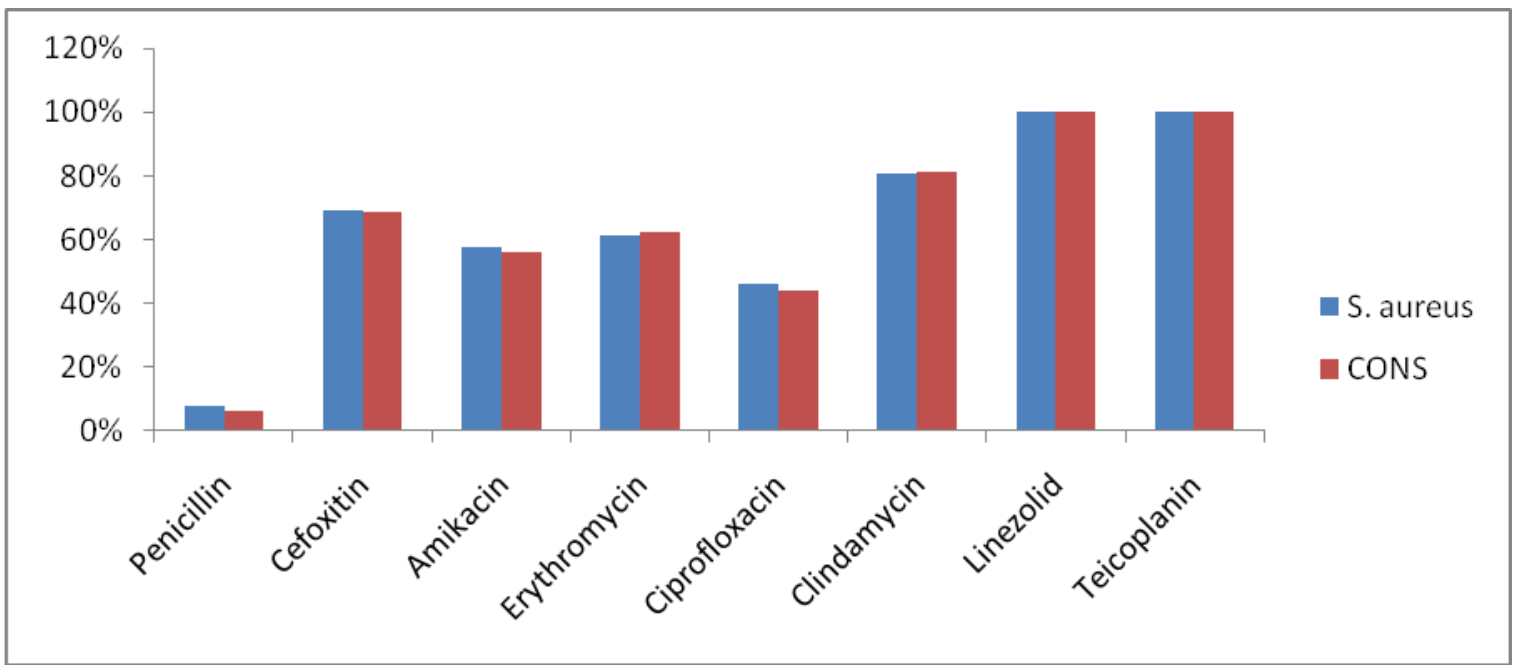

Even in our study similar time related changes were observed. Gram positive cocci were the most common isolate on Day 1 while gram negative bacilli were isolated more from swabs collected on Day 4 and Day 10 from the same patients (Table 2)

With the above results, it is emphasized that empirical Antibiotics on day one should focus on Gram positive agents as skin normal flora will come into act as a pathogen and from $3^{\text {rd }}$ day onwards on gram negative bacilli.

In our study the predominant organisms isolated (Fig 3) were Pseudomonas aeruginosa [35.84\%], Klebsiella species [27.30\%], Acinetobacter species [20.13\%], Escherichia coli [2.38\%] Staphylococcus aureus [8.87\%] and CONS [5.46\%].

Our findings concerning the high frequency of Pseudomonas aeruginosa (35.84\%) (Fig) coincide with many previous reports (Kaur $e t$ al., (2006)., Rajput et al., (1998), Mundhada et al., (2015)) where this organism was held responsible for majority of burn wound infections. The most common combination was Pseudomonas aeruginosa with Klebsiella species or Acinetobacter species or both. This might be probably because of its ability to resist the effect of antibiotics due to its intrinsic and acquired resistant mechanisms.

Acinetobacter species was isolated at a rate of $20.13 \%$ which is higher than the rate of isolation reported from previous studies Mundahada et al., and De Macedo et al., This finding is of great concern as it signifies its emerging trend as predominant pathogen in recent past.

The human skin is constantly bombarded by microbes from environment. Staphylococcus aureus, normal flora of healthy individual could become pathogenic when host defense is compromised as in burns patients (Chaya kumar et al.,). Hospital environment in burn units have become reservoir for S.aureus which favor them to be a major nosocomial pathogen (Wildemauee et al., 2004).

S.aureus was the predominant pathogen in the pre antibiotic era, still posing threat in burn patients. Isolation rate was $8.87 \%$ which is less comparable to the findings reported by Saha et al., (2011) (16\%). Among the Staphylococcus aureus-36.6\% were MRSA (Table 3). 
Antibiotic Susceptibility Pattern of gram negative bacteria showed high susceptibility to Imipenem (98\% -100\%) and Piperazillin Tazobactem $\quad(67 \% \quad-100 \%)$, least susceptibility was observed for Cefotaxime (20\%-53\%), Ceftazidime (32\% -42\%) and Ampicillin (16\% - 42\%). According to Chayakumar et al., (2010) and Saxena et al., (2013), high level of resistance was observed for Ceftazidime. Our finding was also similar to these studies. Gram positive organisms were found to be susceptible to Amikacin (57\%), Clindamycin(81\%), Linezolid (100\%), and Teicoplanin (100\%) (Fig 4 \& Fig 5). Least susceptibility was observed for Penicillin (8\%). This is in accordance with the results of Mundahda et al., (2015).

In conclusion, time related changes of bacterial flora have been observed. Based on our findings we emphasize need for every burn institute to determine its specific pattern. It is also crucial to formulate prophylactic and therapeutic strategies of burn institution.

\section{References}

AL-Aali, K.Y. 2016. Microbial Profile of Burn Wound Infections in Burn Patients, Taif, Saudi Arabia. Arch. Clin. Microbiol., 7: 2.

Al-Akayleh, A.T. 1999. Invasive burn wound infection. Annals of Burns and Fire Disasters, 7: 1-3.

Demacedo, J.L., Santos, J.B. 2005. Bacterial and fungal colonization of burn wounds. Mem Inst Oswaldo Cruz., 100: 535-539.

Kaur, H., Bhat, J., Anvikar, A.R., Rao, S., Gadge, V. 2006. Bacterial profile of blood and burn wound infections in burn patients. Proc. Natl. Symp. Tribal Health, 89-95.

Lari, A.R., Alaghehbandan, R., Nikui, R. 2000. Epidemiological study of 3341 burns patients during three years in Tehran, Iran. Burns, 26: 49-53.
Liwimbi, O.M., Komolafe, I.O. 2007. Epidemiology and bacterial colonization of burn injuries in Blantyre. Malawi Med. J., 19: 25-7.

Mundhada, S.G., Waghmare, P.H., Rathod, P.G., Ingole, K.V. 2015. Bacterial and fungal profile of burn wound infections in Tertiary Care Center. Indian J. Burns, 23: 71-5.

Modi, S., Anand, A.K., Chachan, S., Prakash, S. 2013. Bacteriological profile and antimicrobial susceptibility patterns of isolates from burn wounds at a tertiary care hospital in Patna. J. Evol. Med. Dent. Sci., 2: 6533-41.

NCCLS. 2003b. National Committee for Clinical Laboratory Standards. Performance Standards for Antimicrobial Disk Susceptibility Tests. 8th Edn., Approved standard M2-A8. National Committee for Clinical Laboratory Standards, Wayne, Pa, USA.

Rajput, A., Singh, K., Kumar, V., Sexena, R., Singh, R. 1998. Antibacterial resistance pattern of aerobic bacteria isolates from burn patients in tertiary care hospital. Ind. Medica, 19: 1-4

Saaiq, M., Ahmad, S., Zaib, M.S. 2015. Burn Wound Infections and Antibiotic Susceptibility Patterns at Pakistan Institute of Medical Sciences, Islamabad, Pakistan. World J. Plast. Surg., 4(1): 9-15.

Shahzad, M.N., Ahmed, N., Khan, I.H., Mirza, A.B., Waheed, F. 2012. Bacterial profile of burn wound infections in burn patients. Ann. Pak. Inst. Med. Sci., 8: 54-7.

Srinivasan, S., Varma, A.M., Patil, A., Saldanha, J. 2009. Bacteriology of the burn wound at the Bai Jerbai Wadia Hospital for children, Mumbai, India A 13-year study, Part I-Bacteriological profile. Indian J. Plast. Surg., 42: 2138. 
Saha, S.K., N. Muazzam, S.A. Begum, A. Chowdhury, M.S. Islam, R. Parveen. 2011. Study on Time-related Changes in Aerobic Bacterial Pattern of Burn Wound Infection Faridpur, Med. Coll. J., 6(1): 41-45.

Saxena, N., Dadhich, D., Maheshwari, D. 2013. Aerobic bacterial isolates from burn wound infection patients and their antimicrobial susceptibility pattern in Kota, Rajasthan. J. Evol. Med. Dent. Sci., 2: 4156-60.

Wildemauee, C., Godard, C., Vershragen, G., Claeys, G., Duyck, C., et al. 2004. Ten years phage typing of Belgian clinical methicillin-resistant $\mathrm{S}$. aureus isolates. J. Hosp. Infect., 56: 16-21.

\section{How to cite this article:}

Sabetha, T., A.V.M. Balaji, J. Nithyalakshmi, K. Mohanakrishnan and Sumathi, G. 2017. Study on Bacterial Flora of Burn Wound Infection: A Need for Microbiological Surveillance in Burn Units. Int.J.Curr.Microbiol.App.Sci. 6(5): 807-815. doi: https://doi.org/10.20546/ijcmas.2017.605.091 